\title{
Background Selection Using DNA Markers in Backcross Breeding Program for Potato Virus Y Resistance of Tobacco
}

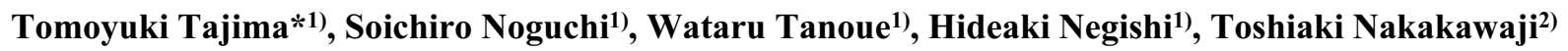 \\ and Takahiro Ohno ${ }^{2)}$ \\ 1) Leaf Tobacco Research Center, Japan Tobacco Inc., 1900 Idei, Oyama, Tochigi 323-0808, Japan \\ 2) Kagoshima Leaf Tobacco Technical Center, Japan Tobacco Inc., 5648-2 Kamifukumoto, Kagoshima 891-0116, Japan
}

The suitability of background selection using DNA markers was assessed in a tobacco backcross breeding program for introgression of a potato virus Y (PVY) resistance gene $(v a / v a)$ derived from a novel resistant source, Kerti No. 1, into the genome background of a commercial variety, Coker319. Ten randomly amplified polymorphic DNA (RAPD) and 76 amplified fragment length polymorphic (AFLP) markers specific to the Kerti No. 1 genome background (background markers) were identified based on the polymorphism analysis with Coker319 and they were used for background selection at loci not linked to $v a$. Two markers flanking $v a$ on each side (linkage markers) were used for background selection of the va-carrying chromosome. In each backcross generation, 200 plants were developed and surveyed with only the background markers, while 300 plants were similarly treated with both the background and linkage markers in the $\mathrm{BC}_{3} \mathrm{~S}_{1}$ generation. One plant, where all the 86 randomly extracted background marker loci and 2 linkage marker loci were recovered in the recipient genotype, was obtained through only 3 backcrossings and 1 selfing. CKM1 $\left(\mathrm{BC}_{3} \mathrm{~S}_{2}\right)$ derived from this $\mathrm{BC}_{3} \mathrm{~S}_{1}$ plant did not display any significant differences from Coker319 in terms of characters (e.g., yield, number of leaves, length and width of leaves, leaf-color change during the maturation period, yellowing rate in the curing process). In addition, CKM1 was similar to Coker319 in terms of aroma, taste and low smoke quality. These results demonstrated that the genomic background of CKM1 was almost identical with that of Coker319 and that background selection on both a carrier and noncarrier chromosome(s) by DNA markers significantly accelerated the progress of a backcross program in tobacco. CKM1 did not display any adverse effects on the line introgressing the PVY resistance derived from other sources. Therefore, Kerti No. 1 appears to be the most suitable source of PVY resistance for tobacco breeding programs.

Key Words: tobacco, background selection, AFLP, RAPD, potato virus Y (PVY), resistance.

Communicated by K. Harada

Received January 9, 2002. Accepted July 3, 2002.

*Corresponding author (e-mail: tomoyuki.tajima@ims.jti.co.jp)

\section{Introduction}

Vein-banding in tobacco caused by PVY is a serious disease that occurs in tobacco-growing areas around the world (de Bokx and Huttinga 1981). In Japan, this virus occurs particularly in the form of the necrotic strain PVY-T. Several resistant varieties are used as potential sources of resistance in breeding programs, and many resistant breeding lines have been developed. However, the genes have not been widely introduced in to tobacco cultivars because of their close association with several adverse effects, which are considered to behave as a linkage drag in agronomic characters (Koelle 1958, Burk and Chaplin 1980, Yamamoto 1992, Nielsen et al. 1982, Sato et al. 1982, Komari et al. 1986). Noguchi et al. (1999) have reported that most of the PVY resistance in tobacco is mainly caused by the deletion of a large genomic segment (probably above the scale of megabase) carrying an allele ( $V a$ ) for PVY susceptibility and that the amount of linkage drags due to PVY resistance was correlated with the size of the genomic segment deleted. An important aspect is that homologous recombination is not expected to occur in the region lacking in resistant varieties, suggesting that mating could not reduce the amount of linkage drags. As such, a PVY-resistant variety, in which the size of the deletion inducing resistance is the smallest, may become the most suitable source for tobacco breeding. We had previously identified an optimal resistance source, Kerti No. 1, and analyses using $V a$-linked RAPD markers failed to distinguish it from the susceptible varieties (Noguchi et al. 1999). It is likely that the size of the mutation in this variety is considerably smaller than that of other resistant varieties. Thus, Kerti No. 1 may be an extremely suitable candidate for PVY resistance in tobacco breeding programs and the effectiveness of its resistance should be assessed immediately.

DNA markers have been used to accelerate the recovery in the recipient parent genotype at the loci without an introgressed locus ("background selection"; Tanksley 1983, Young and Tanksley 1989, Hillel et al. 1990), and the efficiency of background selection has been demonstrated (Hospital et al. 1992, Visscher et al. 1996). In spite of their suitability, DNA markers, however, are seldom used in tobacco breeding programs, especially for background selection. In this study, $v a$ from Kerti No. 1 was introgressed into the genome background of a commercial variety 'Coker319' in a marker-assisted backcross program. To implement this 
program as rapidly and efficiently as possible, we used randomly selected genomic markers and two $v a$-linking markers for the selection. The findings may be able to assess the suitability of background selection using DNA markers in tobacco and the effectiveness of the PVY resistance of Kerti No. 1 through the evaluation of the properties of the finally selected $\mathrm{BC}_{3} \mathrm{~S}_{2}$ plants.

\section{Materials and Methods}

\section{Plant materials}

Coker319, the most cultivated flue-cured variety in Japan, was used as the recipient parent, while Kerti No. 1 (Hungarian domestic air-cured variety) was used as the donor parent of PVY resistance. The PVY resistance of Kerti No. 1 derived from the recessive allele $(v a)$ of the gene $(V a)$ for PVY susceptibility was referred to as $v a$. Three backcrossings, $($ Coker319 $\times$ Kerti No. 1$) \times$ Coker319, were performed, and 200 plants were surveyed in each backcross generation. In the $\mathrm{BC}_{3} \mathrm{~S}_{1}$ generation, 300 plants were surveyed.

\section{Identification of $\mathrm{Va} / \mathrm{va}$ plants}

To identify $V a / v a$ plants from each backcross generation, a testcross with Kerti No. 1 and an inoculation test of PVY-T were carried out. The inoculation tests of PVY-T were conducted in the same way as described by Yamamoto (1992). Four-week-old seedlings were transplanted to plastic seedling pots and grown in a temperature-controlled greenhouse at $20-25^{\circ} \mathrm{C}$. After about 10 days, PVY-T was inoculated into the largest leaf of each seedling. The inocula were prepared as follows: $1 \mathrm{~g}$ of tobacco leaves infected with PVY-T was homogenized with a small quantity of water before the homogenate was diluted with water to $100 \mathrm{ml}$. After 3 weeks, the presence of disease symptoms was investigated.

\section{Identification of background markers}

RAPD and AFLP analyses for the detection of the Kerti No. 1-specific polymorphic DNA fragments were performed (Williams et al. 1990, Noguchi et al. 1999, Vos et al. 1995). The decamer primers for RAPD were obtained from Operon Technologies (Operon kits E-J) and all the primer pairs obtained from three combinations of primer kits, OPE vs OPF, OPG vs OPH and OPI vs OPJ, were used. For AFLP analysis, combinations of restriction enzymes (MseI/Pst I and $M s e \mathrm{I} / E c o \mathrm{RI}$ ) were used. The amplification primers consisted of a core sequence of adaptors, an enzyme-specific sequence with selective extensions. The number of nucleotides of the selective extensions of MseI-primers was 4, while that of PstI- and EcoRI-primers was 3. An ABI PRISM 377 DNA Sequencer and GeneScan software (Applied Biosystems) were used for AFLP analysis. Segregation of the polymorphic DNA fragments detected from Kerti No. 1 DNA was subsequently screened using a segregating population (10-20 $\mathrm{BC}_{1}$ plants).

\section{Va-linking markers}

$V a$-linking RAPD markers (Noguchi et al. 1999) were converted to STS markers and the sequences of their PCR products from Coker319 and Kerti No. 1 were searched for single nucleotide polymorphism (SNP). SNPs were observed in 2 marker fragments (O5V6 and K8). Linkage analysis using $200 \mathrm{BC}_{1}$ plants clarified the order of the loci on the $V a$-carrying chromosome; vizO5V6, (5.5 cM), Va, (9 $\mathrm{cM}$ ) and K8 (data not shown).

\section{Results}

\section{$B C_{1}$ selection}

Ten RAPD and 43 AFLP markers specific to the Kerti No. 1 genome background were identified based on polymorphism analysis between Kerti No. 1 and Coker 319 using 570 pairs of RAPD primers and 336 pairs of AFLP primers (MseI- and PstI- primer), respectively. Following the identification of the $\mathrm{Va} / \mathrm{va}$ plants, the presence of these 53 markers was surveyed in all of the $106 \mathrm{Va} / \mathrm{va}$ and $70 \mathrm{Va} / \mathrm{Va} \mathrm{BC}_{1}$ plants. The number of markers in each plant ranged from 9 to 43 (data not shown). The plant carrying the smallest number of markers (13 markers) among the $\mathrm{Va} / \mathrm{va}$ plants was No. 189 (Table 1), which was thus selected in this generation. No markers were linked to $v a$ (data not shown).

\section{$B C_{2}$ selection}

Thirty-three AFLP markers were newly identified based on polymorphism analysis between the No. 189 plant and Coker319 using 429 pairs of AFLP primers (MseI- and EcoRI- primers). A total of 46 markers (13 which persisted in the $\mathrm{BC}_{1}$ selection and 33 new ones) enabled to perform 2stage background selection in this $\mathrm{BC}_{2}$ generation. At the first stage, $200 \mathrm{BC}_{2}$ plants derived from $\mathrm{BC}_{1}-\mathrm{No}$. 189 were surveyed with 28 markers. The numbers of markers in each plant in this generation ranged from 5 to 23 . Thirty-three plants carrying 5 to 13 markers were selected at this primary stage (data not shown). At the following stage, the presence of the remaining 18 markers was surveyed in the plants selected at the primary stage. The count in these plants ranged from 12 to 26 of a total of 46 markers (data not shown). No. 189-36, a $V a / v a$ plant with a minimum of 12 markers, was selected in this $\mathrm{BC}_{2}$ generation (Table 1). None of the newly identified markers were linked to $v a$ (data not shown).

\section{$\mathrm{BC}_{3}$ selection}

$\mathrm{BC}_{3}$ selection was performed with $200 \mathrm{BC}_{3}$ plants using 12 markers carried in $\mathrm{BC}_{2}$ 189-36. No. 189-36-118 and No. 189-36-169, Va/va plants with 3 and 2 markers respectively, were selected in this generation (Table 1).

\section{$B C_{3} S_{1}$ selection}

Seventy va/va plants (resistant $\mathrm{BC}_{3} \mathrm{~S}_{1}$ ) were selected each from the 300 self-cross progenies of No. 189-36-118 and No. 189-36-169, respectively. Genotyping at the O5V6 and K8 marker loci linked to $V a$ was executed in these prog- 
Table 1. Progress of introgression of PVY resistance ( $v a / v a$ ) from Kerti No. 1 into the genome background of a commercial variety Coker 319 in a marker-assisted backcross program

\begin{tabular}{|c|c|c|c|c|c|c|c|c|c|}
\hline \multirow[t]{2}{*}{ Generation } & \multirow[t]{2}{*}{ Donor } & \multirow{2}{*}{$\begin{array}{l}\text { Total no. } \\
\text { of plants }\end{array}$} & \multirow[t]{2}{*}{ Selected plant } & \multicolumn{3}{|c|}{$\begin{array}{l}\text { No.of background } \\
\text { markers }^{1)}\end{array}$} & \multicolumn{3}{|c|}{$\begin{array}{l}\text { Genotype at the linkage } \\
\left.\text { marker loci }{ }^{2}\right) \text { and } V a(v a)\end{array}$} \\
\hline & & & & ng & Total & $(\%)$ & O5V8 & $V a(v a)$ & K8 \\
\hline $\mathrm{BC}_{1}$ & Coker $319 \times$ Kerti No. 1 & 200 & No. 189 & 13 & 53 & $(24.5)$ & - & $\mathrm{C} / \mathrm{K}^{3)}$ & - \\
\hline $\mathrm{BC}_{2}$ & No. 189 & 200 & No. $189-36$ & 12 & 86 & $(14.0)$ & - & $\mathrm{C} / \mathrm{K}$ & - \\
\hline \multirow[t]{2}{*}{$\mathrm{BC}_{3}$} & No. $189-36$ & 200 & No. 189-36-118 & 3 & 86 & $(3.5)$ & - & $\mathrm{C} / \mathrm{K}$ & - \\
\hline & & & No. 189-36-169 & 2 & 86 & $(2.3)$ & - & $\mathrm{C} / \mathrm{K}$ & - \\
\hline \multirow[t]{3}{*}{$\mathrm{BC}_{3} \mathrm{~S}_{1}$} & No. 189-36-118 & 300 & No. 189-36-118-9 (CKM1) & 0 & 86 & $(0)$ & $\mathrm{C} / \mathrm{C}$ & $\mathrm{K} / \mathrm{K}$ & $\mathrm{C} / \mathrm{C}$ \\
\hline & No. 189-36-169 & 300 & No. 189-36-169-24 (CKM2) & 0 & 86 & $(0)$ & $\mathrm{K} / \mathrm{K}$ & $\mathrm{K} / \mathrm{K}$ & $\mathrm{C} / \mathrm{C}$ \\
\hline & & & No. 189-36-169-63 (CKM3) & 0 & 86 & (0) & $\mathrm{K} / \mathrm{K}$ & $\mathrm{K} / \mathrm{K}$ & $\mathrm{C} / \mathrm{C}$ \\
\hline
\end{tabular}

1) The markers were specific to Kerti No. 1 genome background but were not linked to $v a$.

2) The markers flanking $v a$ on each side

3) C: Coker319, K: Kerti No. 1

enies. In one $\mathrm{BC}_{3} \mathrm{~S}_{1}$ plant from No. 189-36-118 (No. 189-36118-9), all the 86 background marker loci and 2 loci flanking $v a$ on each side were recovered in the recipient genotype (Table 1). Two plants (No. 189-36-169-24, No. 189-36-16963) from the No. 189-36-169 progeny did not carry any background markers. In these plants, only the K8 marker locus flanking $v a$ on one side was recovered in the recipient genotype (Table 1). These 3 plants were selected in this generation, and their $\mathrm{BC}_{3} \mathrm{~S}_{2}$ progenies were obtained. The 3 lines obtained were referred to as CKM1, CKM2 and CKM3, respectively.

\section{Field trials}

The growth characters (flowering date, length and width of leaves, plant height and number of leaves) of CKM1, CKM2 and CKM3 during the flowering period were surveyed in the field (Table2, Table 3). No significant differ- ences were observed between CKM1 and Coker319 except that the former showed a narrower leaf width at the central position of the stalk than Coker319 (Fig. 1). The CKM2 line flowered 2 days earlier, was taller by $10 \mathrm{~cm}$ and had smaller leaves than Coker319. The CKM3 line flowered 1 day later, was taller by $10 \mathrm{~cm}$ and had one more leaf than Coker 319 . In terms of leaf color change during the maturation period, CKM1 was identical with Coker319 but was different from CKM2 and CKM3 (Table 4). The changes in the yellowing rate and relative leaf weight in the curing process were compared with those of Coker319 (Table 5). No significant differences in the yellowing rate were observed between CKM1 and Coker319, except that CKM1 displayed a slightly slower yellowing of leaves after $18 \mathrm{hr}$ of curing compared with Coker319. No significant differences were observed between the 3 lines and Coker319 in the relative leaf weight. Yield of CKM1 was identical with that of Coker319 but was

\section{Coker 319}

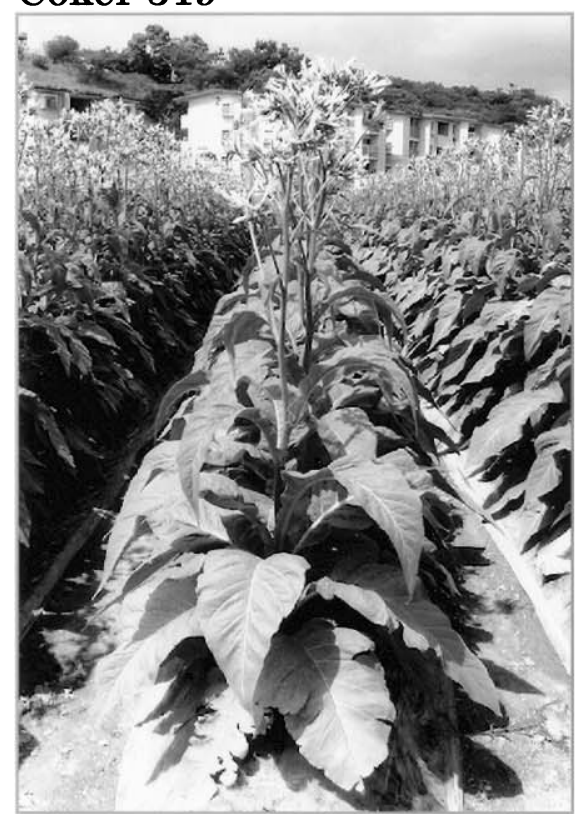

\section{CKM 1}

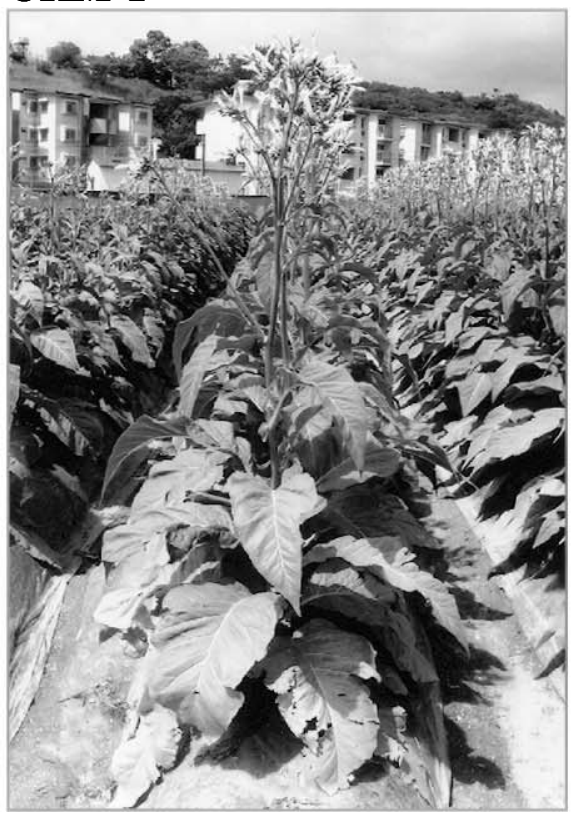

Kerti No.1

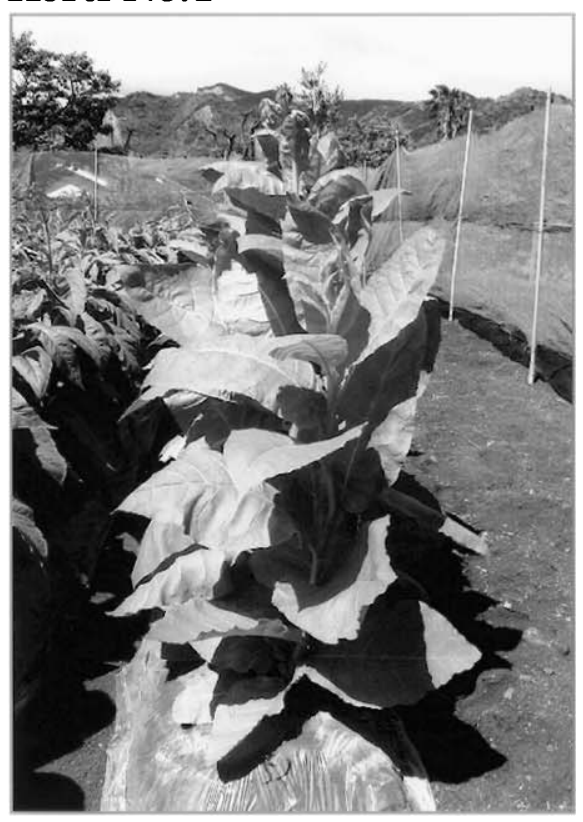

Fig. 1. Comparison of morphological characters between CKM1 $\left(\mathrm{BC}_{3} \mathrm{~S}_{2}\right)$ and parents cultivars at the flowering stage. 
Table 2. Flowering date and length and width of leaves of $\mathrm{CKM} \mathrm{BC}_{3} \mathrm{~S}_{2}$ lines during the flowering period

\begin{tabular}{|c|c|c|c|c|c|c|c|}
\hline \multirow{3}{*}{ Lines } & \multirow{3}{*}{$\begin{array}{c}\text { Flowering } \\
\text { date }^{1)}\end{array}$} & \multicolumn{6}{|c|}{ Position from the top of plant } \\
\hline & & \multicolumn{2}{|c|}{$1 / 4$} & \multicolumn{2}{|c|}{$1 / 2$} & \multicolumn{2}{|c|}{$3 / 4$} \\
\hline & & Length $^{3)}$ & Width $^{3)}$ & Length & Width & Length & Width \\
\hline CKM1 & $63.9 \mathrm{~b}^{2)}$ & $56.5 \mathrm{~b}$ & $16.2 \mathrm{a}$ & $67.2 \mathrm{~b}$ & $25.4 \mathrm{ab}$ & $63.5 \mathrm{ab}$ & $33.6 \mathrm{~b}$ \\
\hline CKM2 & $62.2 \mathrm{a}$ & $53.9 \mathrm{a}$ & $17.1 \mathrm{a}$ & $64.3 \mathrm{a}$ & $25.0 \mathrm{a}$ & $61.8 \mathrm{a}$ & $31.3 \mathrm{a}$ \\
\hline CKM3 & $65.6 \mathrm{c}$ & $57.1 \mathrm{~b}$ & $16.0 \mathrm{a}$ & $68.7 \mathrm{~b}$ & $26.9 \mathrm{bc}$ & $66.0 \mathrm{~b}$ & $35.0 \mathrm{~b}$ \\
\hline Coker319 & $64.3 \mathrm{~b}$ & $56.5 \mathrm{~b}$ & $17.0 \mathrm{a}$ & $67.4 \mathrm{~b}$ & $27.6 \mathrm{c}$ & $63.8 \mathrm{ab}$ & $34.5 \mathrm{~b}$ \\
\hline
\end{tabular}

1) Days after transplanting.

2) Means with the same letter in the same column are not significantly different with $\mathrm{P}=0.05$.

3) The unit was expressed in $\mathrm{cm}$.

Table 3. Plant height and number of leaves of $\mathrm{CKM} \mathrm{BC}_{3} \mathrm{~S}_{2}$ lines during the flowering period

\begin{tabular}{lccccc}
\hline \hline \multirow{2}{*}{ Lines } & $\begin{array}{c}\text { Plant height } \\
(\mathrm{cm})\end{array}$ & \multicolumn{4}{c}{ Number of leaves on the stalk per plant } \\
\cline { 3 - 6 } & & $0-30 \mathrm{~cm}$ & $30-60 \mathrm{~cm}$ & $60-\mathrm{cm}$ & Total \\
\hline CKM1 & $143 \mathrm{a}^{1)}$ & $10.7 \mathrm{a}$ & $5.2 \mathrm{ab}$ & $3.4 \mathrm{a}$ & $19.3 \mathrm{a}$ \\
CKM2 & $151 \mathrm{~b}$ & $10.3 \mathrm{a}$ & $4.9 \mathrm{a}$ & $4.0 \mathrm{~b}$ & $19.2 \mathrm{a}$ \\
CKM3 & $152 \mathrm{~b}$ & $10.6 \mathrm{a}$ & $5.7 \mathrm{c}$ & $4.8 \mathrm{c}$ & $21.0 \mathrm{~b}$ \\
Coker319 & $141 \mathrm{a}$ & $10.7 \mathrm{a}$ & $5.6 \mathrm{bc}$ & $3.4 \mathrm{a}$ & $19.7 \mathrm{a}$ \\
\hline
\end{tabular}

1) Means with the same letter in the same column are not significantly different with $\mathrm{P}=0.05$.

Table 4. Leaf color change of $\mathrm{CKM} \mathrm{BC}_{3} \mathrm{~S}_{2}$ lines during the maturation period

\begin{tabular}{|c|c|c|c|c|}
\hline \multirow{3}{*}{ Lines } & \multicolumn{4}{|c|}{ Leaf color } \\
\hline & \multicolumn{4}{|c|}{ After topping (days) } \\
\hline & 7 & 21 & 35 & 49 \\
\hline CKM1 & $37.0^{1)} \mathrm{a}^{2)}$ & $24.3 \mathrm{a}$ & $14.6 \mathrm{a}$ & $10.9 \mathrm{a}$ \\
\hline CKM2 & $41.0 \mathrm{~b}$ & $33.6 \mathrm{~b}$ & $23.2 \mathrm{~b}$ & $14.4 \mathrm{bc}$ \\
\hline CKM3 & $42.2 \mathrm{~b}$ & $35.7 \mathrm{~b}$ & $28.7 \mathrm{c}$ & $17.0 \mathrm{c}$ \\
\hline Coker319 & 37.0 & $26.6 \mathrm{a}$ & $15.8 \mathrm{a}$ & $11.7 \mathrm{ab}$ \\
\hline
\end{tabular}

1) Value measured with chlorophyll meter (SPAD value). A larger value corresponds to a darker green color. The leaf positioned $1 / 2$ from the top.

2) Means with the same letter in the same column are not significantly different with $\mathrm{P}=0.05$. different from that of CKM2 and CKM3 (Table 6). No significant differences in the total alkaloid content were observed between the 3 lines and Coker319 (Table 6).

\section{Discussion}

Background selection by DNA markers significantly accelerated the backcross program. CKM189-36-118-9 $\left(\mathrm{BC}_{3} \mathrm{~S}_{1}\right)$, where all the 86 randomly selected background loci and 2 loci flanking $v a$ on each side were recovered in the recipient genotype, appeared through only 3 backcrossings and 1 selfing. $\mathrm{CKM} 1\left(\mathrm{BC}_{3} \mathrm{~S}_{2}\right)$ derived from this $\mathrm{BC}_{3} \mathrm{~S}_{1}$ plant showed the same characters in terms of growth, maturation and curing as the recipient parent, Coker319. The characters of CKM1 $\left(\mathrm{BC}_{3} \mathrm{~S}_{2}\right)$ did not differ significantly from those of Coker319 in terms of flowering date, plant height, number of leaves, length and width of leaves, leaf-color change during the maturation period, yellowing rate and relative leaf weight in the curing process, yield and total alkaloid content. In addition, CKM1 was similar to Coker319 in terms of aroma, taste and low smoke quality (data not shown). These results demonstrated that the genomic background of CKM1 was almost identical with that of the recipient parent, Coker 319.

However, in CKM2 and CKM3 $\left(\mathrm{BC}_{3} \mathrm{~S}_{2}\right)$ derived from CKM189-36-169-24 and 189-36-169-63, respectively, sev-

Table 5. Yellowing rate and relative leaf weight in the curing process (central stalk position)

\begin{tabular}{ccccccc}
\hline \hline \multirow{2}{*}{ Item } & \multicolumn{7}{c}{ Curing time (hours) } & \multirow{2}{*}{$\begin{array}{c}\text { End of } \\
\text { curing }\end{array}$} \\
\cline { 2 - 4 } & 0 & 16 & 22 & 26 & 39 & \\
\hline Yellowing rate (\%) & & & & & \\
CKM1 & $\left.4.9 \mathrm{a}^{2}\right)$ & $71.1 \mathrm{c}$ & $82.6 \mathrm{c}$ & $92.0 \mathrm{c}$ & $99.3 \mathrm{c}$ & \\
CKM2 & $5.2 \mathrm{~b}$ & $53.6 \mathrm{a}$ & $64.1 \mathrm{~b}$ & $72.8 \mathrm{~b}$ & $83.0 \mathrm{~b}$ & \\
CKM3 & $5.4 \mathrm{~b}$ & $42.3 \mathrm{a}$ & $49.0 \mathrm{a}$ & $54.4 \mathrm{a}$ & $68.5 \mathrm{a}$ & \\
Coker319 & $4.8 \mathrm{a}$ & $62.4 \mathrm{bc}$ & $77.6 \mathrm{c}$ & $90.9 \mathrm{c}$ & $99.2 \mathrm{c}$ & \\
\hline Relative leaf weight (\%) & & & & & & \\
CKM1 & 100 & $81.3 \mathrm{a}$ & $72.2 \mathrm{a}$ & $65.9 \mathrm{a}$ & $49.2 \mathrm{a}$ & $11.0 \mathrm{a}$ \\
CKM2 & 100 & $78.4 \mathrm{a}$ & $67.8 \mathrm{a}$ & $60.0 \mathrm{a}$ & $41.2 \mathrm{a}$ & $10.7 \mathrm{a}$ \\
CKM3 & 100 & $78.5 \mathrm{a}$ & $68.5 \mathrm{a}$ & $61.6 \mathrm{a}$ & $43.9 \mathrm{a}$ & $11.1 \mathrm{a}$ \\
Coker319 & 100 & $81.5 \mathrm{a}$ & $72.2 \mathrm{a}$ & $66.2 \mathrm{a}$ & $49.7 \mathrm{a}$ & $11.3 \mathrm{a}$ \\
\hline
\end{tabular}

1) Value measured with a color scale. A larger value corresponds to a darker green color.

2) Means with same letter in the same column are not significantly different with $\mathrm{P}=0.05$. 
Table 6. Yield and total alkaloid content of $\mathrm{CKM} \mathrm{BC}_{3} \mathrm{~S}_{2}$ lines

\begin{tabular}{lccc}
\hline \hline \multirow{2}{*}{ Lines } & Yield $(\mathrm{kg} / 10 \mathrm{a})$ & \multicolumn{2}{c}{ Total alkaloid content $(\%)$} \\
\cline { 3 - 4 } & & LM $^{1)}$ & LH $^{2}$ \\
\hline CKM1 & $238 \mathrm{~b}^{3)}$ & $2.34 \mathrm{a}$ & $3.79 \mathrm{a}$ \\
CKM2 & $189 \mathrm{a}$ & $2.78 \mathrm{a}$ & $3.99 \mathrm{a}$ \\
CKM3 & $211 \mathrm{ab}$ & $2.01 \mathrm{a}$ & $3.42 \mathrm{a}$ \\
Coker319 & $246 \mathrm{~b}$ & $2.45 \mathrm{a}$ & $3.98 \mathrm{a}$ \\
\hline
\end{tabular}

1) Leaves at central stalk position.

2) Leaves at high stalk position.

3) Means with same letter in the same column are not significantly different with $\mathrm{P}=0.05$.

eral adverse effects on these characters were observed. In spite of the fact that CKM2 and CKM3 did not carry any background markers except for 1 locus flanking $v a$, their characters were different from those of Coker 319 in some aspects (e.g., yield, leaf-color change during the maturation period and yellowing rate in the curing process). Some of the differences are probably due to the linkage drags of $v a$. Since CKM2 and CKM3 showed different characters in several aspects, it is assumed that the reduction in the amount of donor genomic background was insufficient in CKM2 and CKM3. These results may imply that the number of background markers used in this program was insufficient. As Hospital et al. (1992) have pointed out that background selection is more efficient in late backcross generations, the fact that we executed this program in early generations may be a cause for concern.

The results of CKM1 revealed that Kerti No. 1 is an optimal source of PVY-T resistance for tobacco breeding programs, as described by Noguchi et al. (1999). This line did not display any of the unfavorable characters, such as earlyflowering, short plant height, small number of leaves, low leaf length and low yield of cured leaves, that were observed in other PVY-T resistant varieties (Yamamoto 1992).

\section{Literature Cited}

Burk,L.G. and J.F.Chaplin (1980) Variation among anther-derived haploids from a multiple disease-resistant tobacco hybrid. Crop Sci. 20: 334-338.

deBokx,J.A. and H.Huttinga (1981) CMI/AAB Descriptions of Plant Viruses, No. 242.

Hillel,J., T.Schaap, A.Haberfeld, A.J.Jeffreys, Y.Plotzky, A.Cahaner and U.Lavi (1990) DNA fingerprints applied to gene introgression breeding programs. Genetics 124: 783-789.

Hospital,F., C.Chevalet and P.Mulsant (1992) Using markers in gene introgression breeding programs. Genetics 132: 1199-1210.

Koelle, G. (1958) Hereditary transmission of resistance to the brownrib disease. CORESTA Inf. Bull 2: 12.

Komari, T., T.Kubo and M.Sato (1986) Inheritance of the lowduvatriendiol trait in Nicotiana tabacum L. Tobacco Sci. 30: 159-162.

Nielsen,M.T., G.A.Jones and G.B.Collins (1982) Inheritance pattern for secreting and nonsecreting glandular trichomes in tobacco. Crop Sci. 22: 1051-1053.

Noguchi, S., T.Tajima, Y.Yamamoto, T.Ohno and T.Kubo (1999) Deletion of large genomic segment in tobacco varieties that are resistant to potato virus Y (PVY). Mol. Gen. Genet. 262: 822829.

Sato,M., T.Komari and K.Asaine (1982) Varietal differences in composition of leaf surface diterpenoids in tobacco. Bull. Iwata Tobacco Experiment Station 14: 59-69.

Tanksley, S.D. (1983) Molecular markers in plant breeding. Plant. Mol. Biol. Rep. 1: 3-8.

Visscher,P.M., C.S.Haley and R.Thompson (1996) Marker-assisted introgression in backcross breeding programs. Genetics 144: 1923-1932.

Vos, P., R. Hogers, M. Bleeker, M. Reijans, T. Lee, M. Hornes, A.Frijters, J.Pot, J.Peleman, M.Kuiper and M.Zabeau (1995) AFLP: a new technique for DNA fingerprinting. Nucleic Acids Res. 23: 4407-4417.

Williams, J.G.K., A.R.Kubelik, K.J.Livak, J.A.Rafalski and S.V. Tingey (1990) DNA polymorphisms amplified by arbitrary primers are useful as genetic markers. Nucleic Acids Res. 18: 6531-6535.

Yamamoto,Y. (1992) Studies on breeding of tobacco varieties resistant to veinal necrosis disease by potato virus $\mathrm{Y}$ strain T. Bull. Leaf Tobacco Research Laboratory 2: 1-85.

Young, N.D. and S.D.Tanksley (1989) RFLP analysis of the size of chromosomal segments retained around the $T m-2$ locus of tomato during backcross breeding. Theor. Appl. Genet. 77: 353-359. 